\title{
The optimal ratio of acquisition and retention costs
}

Received (in revised form): 20th September, 2004

\section{Phillip E. Pfeifer}

is Alumni Research Professor of Business Administration at the Darden Graduate School of Business at the University of Virginia. He teaches courses in interactive marketing and quantitative analysis

\begin{abstract}
It is often said that the cost to acquire a new customer is five times (5X) the cost of retaining an existing one, and therefore firms should spend more money on customer retention. The purpose of this paper is explore whether, in fact, a firm should spend more money on customer retention if its cost to acquire a new customer is $5 \mathrm{X}$ the cost of retaining an existing one. Under the assumptions of the Blattberg and Deighton model, ${ }^{1}$ the answer depends on whether the costs in question are average or marginal. If the $5 \mathrm{X}$ ratio refers to average costs, then a $5 \mathrm{X}$ ratio does not necessarily imply the firm should spend more on retention. If the 5X ratio refers to marginal costs, the firm should either spend more on retention, less on acquisition or both. The optimality conditions of the Blattberg and Deighton model require that the marginal cost to acquire a customer equal the marginal cost to retain a customer and that both will equal the expected customer lifetime value.
\end{abstract}

\section{INTRODUCTION}

An often repeated maxim of interactive marketing goes something like this:

'It costs five times more to acquire a new customer than to retain an existing one'.

Although there is disagreement about the exact numerical ratio of cost to acquire to cost to retain (Sterne documents quoted ratios of three, five, six, ten, 11, 12 and 20), ${ }^{2}$ there is general agreement about the implication of the maxim: firms should devote more attention and money to customer retention.

The purpose of this paper is not to question the veracity of the $5 \mathrm{X}$ maxim

Phillip E. Pfeifer

Darden Graduate School of Business,

PO Box 6550

Charlottesville, VA 22906-6550, USA.

e-mail: PfeiferP@virginia.edu or to estimate the correct ratio. The purpose of this paper is to examine critically the maxim's implications with respect to retention spending. If the cost to acquire a new customer is $5 \mathrm{X}$ the cost to retain an existing customer, should the firm necessarily spend more money on customer retention?

To answer this last question, a model built specifically to determine the optimal mix of acquisition and retention spending is used. Blattberg and Deighton used a decision-calculus approach to construct a simple model that helps managers find the optimal balance between acquisition and retention spending. ${ }^{3}$ This model is used to show that the implications of a $5 \mathrm{X}$ cost ratio depend on whether the $5 \mathrm{X}$ maxim refers to average or marginal costs. If the maxim refers to average costs, then a $5 \mathrm{X}$ ratio does not necessarily mean the firm should spend more on customer acquisition. It will be shown that a $5 \mathrm{X}$ ratio of average costs can be optimal. If, however, the maxim refers to marginal costs, a $5 \mathrm{X}$ ratio means the firm should either increase its 
retention spending, decrease its acquisition spending or both.

In the next section the details of the Blattberg and Deighton (BD) model are reviewed and expressions for average and marginal costs per acquired and retained customer are derived. It will be argued that the optimisation procedure proposed in Blattberg and Deighton is not correct and an alternative will be proposed. In particular, a closed-form expression for the optimal acquisition spending for a given level of retention spending will be derived. A numerical example will then be used to illustrate that, at optimality, the marginal cost to acquire a new customer will equal the marginal cost to retain an existing customer and both will equal the optimal expected lifetime value of a customer. In the subsequent section a carefully constructed numerical example is presented for which the optimal ratio of average cost to acquire to cost to retain is five. This example demonstrates that a $5 \mathrm{X}$ ratio of average costs can be optimal. The paper ends with a brief discussion.

\section{THE BLATTBERG AND DEIGHTON MODEL}

Blattberg and Deighton proposed a simple model for helping managers determine the optimal balance between acquisition and retention spending. The BD model is the result of a decision-calculus approach that breaks down a complex problem into smaller, simpler elements and asks the manager to form judgments about each element separately. The approach then uses a formal model (an equation) to combine the judgments into the answer to a more complex question.

\section{Cost to acquire customers}

The model assumes that $a$, the acquisition rate per prospect, is a decelerating function of $A$, acquisition spending per prospect:

$$
a=C R_{a}\left[1-\exp \left(-k_{a} A\right)\right]
$$

Parameter $C R_{a}$, the acquisition ceiling rate, is the manager's direct assessment of the maximum proportion of targeted prospects that would be converted if there were no limit to spending. Parameter $k_{a}$ can next be determined once the manager gives the current acquisition spending level and the current acquisition rate. The form of this function is consistent with an assumption of strictly diminishing returns to acquisition spending.

To illustrate, consider the numerical example in Blattberg and Deighton ${ }^{4}$ where a manager says 'We spent $\$ 5$ per prospect to attempt to induce a first transaction, and we succeeded $20 \%$ of the time ... I don't think we could ever induce more than $40 \%$ of our prospect pool to become first time customers'. From these two statements, it is determined that $C R_{a}=0.4$ and $k_{a}=0.13863$. Figure 1 shows the complete curve relating the acquisition rate per prospect to the dollar acquisition spending per prospect. Notice that the curve starts at the origin (zero spending means zero acquisitions), goes through the point $(\$ 5,0.2)$, and increases asymptotically to the ceiling rate.

To explore the implications of the BD model with respect to the costs to acquire customers, it is necessary to look at the inverse of function (1).

$$
A=-\left(1 / k_{a}\right) \ln \left[\left(C R_{a}-a\right) / C R_{a}\right]
$$

Equation (2) gives the total acquisition cost per prospect as a function of the desired acquisition rate. The higher the desired acquisition rate, the higher the required cost per prospect. Dividing both sides of (2) by a gives an equation for 


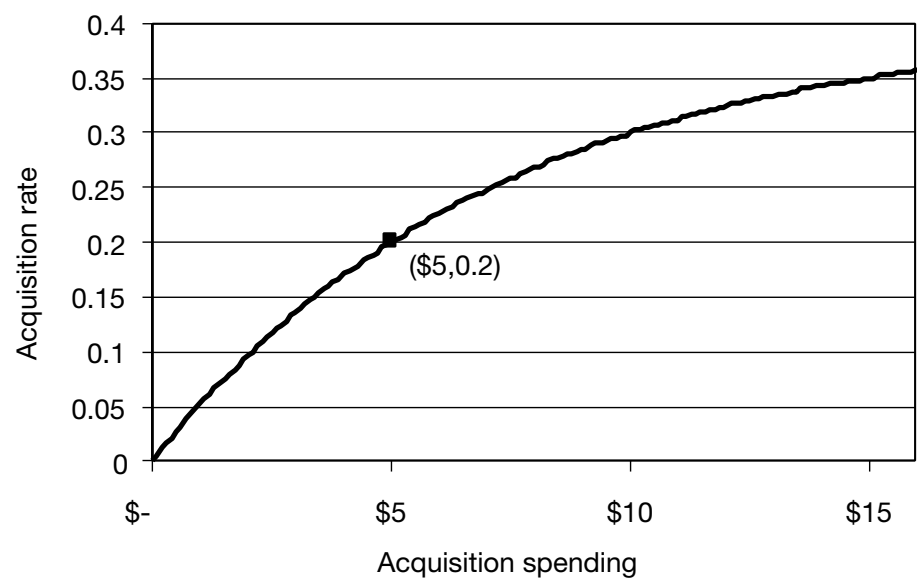

Figure 1 Acquisition rate curve $\left(C R_{a}=0.40, k_{a}=0.13863\right)$

the average cost per acquired customer.

Average cost per acquired customer $\equiv A / a=-\left(1 / k_{a}\right) \ln \left[\left(C R_{a}-a\right) / C R_{a}\right] / a$.

(Notice that average cost is defined to be $A / a$ and that it is recognised that $A / a$ is not the expected value of the ratio of acquisition spending to the number of customers acquired. Because the number of customers acquired may be zero with some probability, the expected value of the ratio of dollars spent to customers acquired does not exist.) Taking the derivative of (2) with respect to a gives an equation for the marginal cost per acquired customer

Marginal cost per acquired customer

$$
\equiv A=\frac{1}{k_{a}\left(C R_{a}-a\right)} \text {. }
$$

Figure 2 graphs the average and marginal cost per acquired customer for the numerical example. Given the strictly diminishing returns inherent in (1), marginal costs are greater than average costs and both increase as the firm more aggressively prospects for new customers.

Figure 2 is the firm's schedule of acquisition costs. At the current spending of $\$ 5$ per prospect, the firm acquires customers at an average cost of $\$ 25.0$ and a marginal cost of $\$ 36.1$. Figure 2 shows how these acquisition costs would change if the firm decided to change its acquisition spending level.

\section{Cost to retain customers}

The BD model uses an identical approach to model the relationship between $r$, the retention rate per customer, and $R$, the dollar retention spending per-customer per-period.

$$
r=C R_{r}\left[1-\exp \left(-k_{r} R\right)\right]
$$

In their numerical example, the manager said 'Last year we spent at the rate of $\$ 10$ per customer and retained $40 \%$ of the customer base ... At best, we might retain $70 \%$ of our customers from one year to the next [if our retention spending were unlimited]'. From these two statements, it is determined that $C R_{r}=0.7$ and $k_{r}=0.08473$. Figure 3 shows the complete curve relating the retention rate per customer to the dollar retention spending per customer. The curve starts at the origin (zero spending 


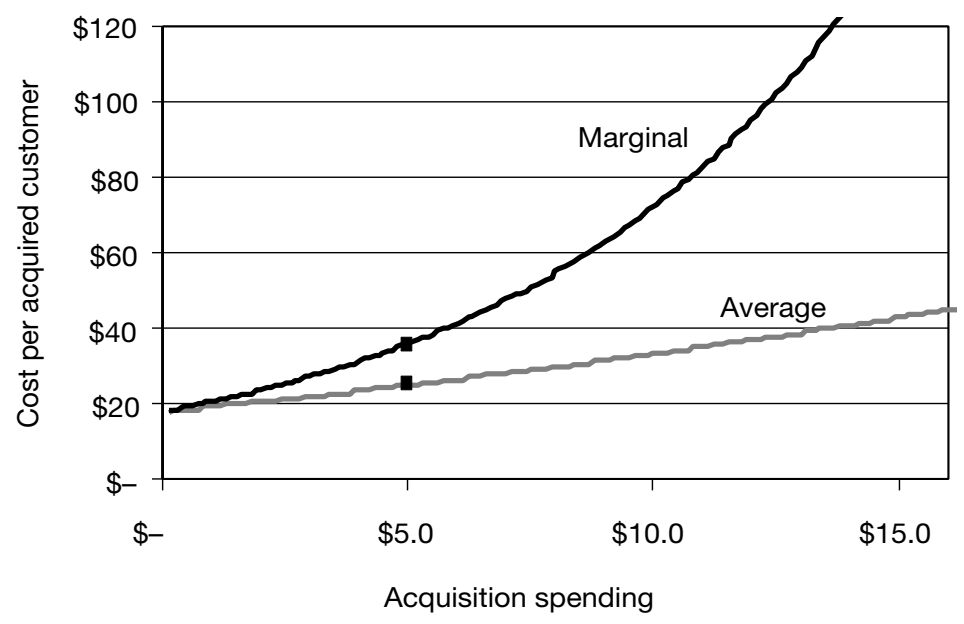

Figure 2 Average and marginal cost per acquired customer $\left(C R_{a}=0.40, K_{a}=0.13863\right)$

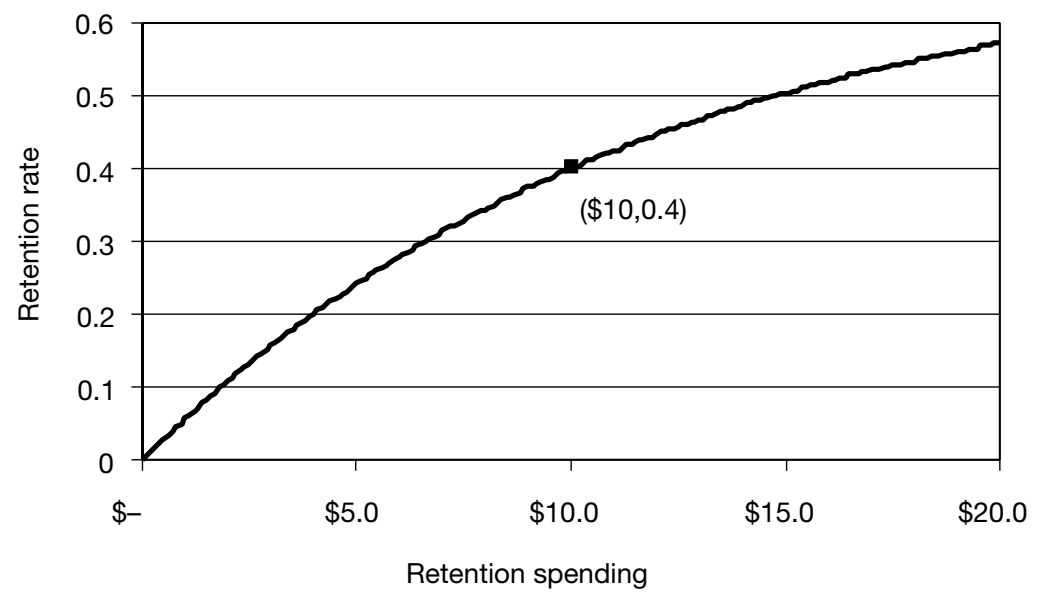

Figure 3 Retention rate curve $\left(C R_{r}=0.70, k_{r}=0.08473\right)$

means zero retention), goes through the point $(\$ 10,0.4)$, and increases asymptotically to the ceiling rate. (The fact that the retention curve goes through the origin is a weakness of the $\mathrm{BD}$ model if the firm expects to retain some percentage of customers even in the absence of retention spending.)

By symmetry, the equations for average cost per retained customer and marginal cost per retained customers are

Average cost per retained customer $\equiv R / r=-\left(1 / k_{r}\right) \ln \left[\left(C R_{r}-r\right) / C R_{r}\right] / r$.
Marginal cost per retained customer

$$
\equiv R^{\prime}=\frac{1}{k_{r}\left(C R_{r}-r\right)} \text {. }
$$

Figure 4 shows these curves for the BD numerical example given above.

Figure 4 is the firm's schedule of retention costs. At the current spending of $\$ 10$ per customer, the firm retains customers at an average cost of $\$ 25.0$ per retained customer and a marginal cost of $\$ 39.3$ per retained customer. Figure 4 shows how these retention costs change if the firm decides to change its retention spending level. 


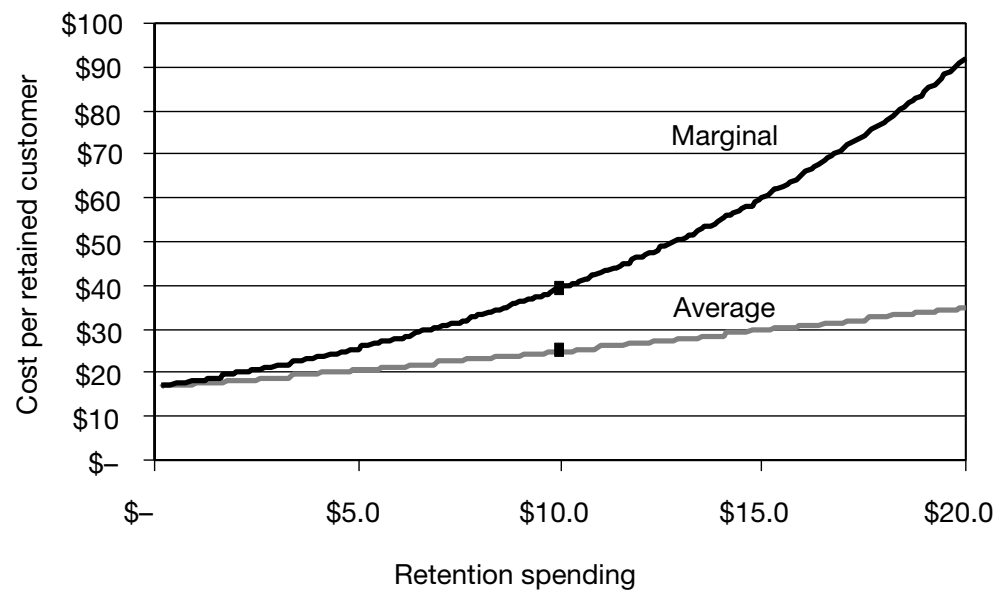

Figure 4 Average and marginal cost per retained customer $\left(C R_{r}=0.70, k_{r}=0.08473\right)$

\section{Maximising expected prospect lifetime value}

The next stage in the $\mathrm{BD}$ analysis is to combine the two spending curves (Figures 1 and 3) with assumptions about the economic consequences of a customer relationship. Let $M$ be the margin the firm earns in any given period of the customer relationship, and let $d$ be discount rate per period. For its investment of $A$ now, with probability $a$ the firm receives $M$ now and spends $R$ at the end of one period. At the end of one period with probability $a \times r$, the firm receives another $M$ and spends another $R$ at the end of two periods. The series of expected cash flows continues with each expected cash flow being $r$ times the previous period's expected cash flow. Notice the assumptions of constant customer margins, constant retention spending and constant retention rate.

Although Blattberg and Deighton name the present value of these expected cash flows 'customer equity', the author prefers the name 'expected prospect lifetime value' (EPLV).

$$
\begin{array}{r}
E P L V=a[M+(M-R / r) \\
\left.\left(\frac{r}{1+d-r}\right)\right]-A
\end{array}
$$

EPLV is the expected present value of spending $A$ dollars on a prospect. One could think of EPLV as the value to the firm of each prospect in the target group.

For the $A$ dollar investment, the firm acquires a customer relationship with probability $a$. The expected present value of the cash flows from the customer relationship is given as

$$
E C L V=M+(M-R / r)\left(\frac{r}{1+d-r}\right),
$$

where ECLV stands for expected customer lifetime value. One could think of ECLV as the value to the firm of a newly acquired customer. The customer's initial $M$ is included in ECLV, but acquisition costs are not.

Defining terms in this way allows the following to be written:

$$
E P L V=a[E C L V]-A .
$$

In words, equation (10) says that the expected value of a prospect is the acquisition rate times the expected value of an acquired customer minus the acquisition spending per prospect.

Given the assumptions underlying (8), the decision problem is now to choose 
$A$ and $R$ to maximise EPLV. $A^{\star}$ and $R^{\star}$ are used to represent the optimal spending amounts, those that maximise EPLV.

It is here that the author departs from the BD approach. Blattberg and Deighton suggested that $A$ be selected to maximise the net contribution from acquiring a customer in the first year, $a M-A$. The author argues this is unnecessarily myopic and suboptimal. The value to the firm of a newly acquired customer is ECLV, a value greater than or equal to $M$. If the firm prospects with the intention of retaining the customers acquired, maximising $E P L V$ is the appropriate objective for a risk-neutral decision maker.

A two-step approach is used to find $A^{\star}$ and $R^{\star}$. First, a numerical optimisation technique (Microsoft Excel Solver) is used to find the $R$ value that maximises ECLV given by (9) recognizing that $r$ is a function of $R$ according to (5). Given $R^{\star}$ and the resulting optimal $E C L V$, the second step is to use equation (11) to find $A^{\star}$ :

$$
A^{\star}=\left(1 / k_{a}\right) \ln \left(k_{a} C R_{a} E C L V^{\star}\right) .
$$

Equation (11) obtains by setting the first derivative of (10) with respect to $A$ equal to zero recognising that $a$ is a function of $A$ according to (3). (The BD suggestion for finding the optimal $A$ is equivalent to replacing $E C L V^{\star}$ with $M$ in equation (11). Since $M \leq E C L V^{\star}$, the $\mathrm{BD}$ approach results in too little investment in customer acquisition.) With $A^{\star}$ and $R^{\star}$ in hand, (3), (4), (6), and $(7)$ can be used to calculate optimal average and marginal costs.

To complete the numerical example, assume $M=\$ 50$ and $d=0.1$. For these values and the retention curve given in Figure 3 , the $R$ value that maximises $E C L V$ is $\$ 16.32$. At $R^{\star}=\$ 16.32$, the firm retains 52.44 per cent of its customers resulting in an ECLV $V^{\star}$ of $\$ 67.20$. For $E C L V^{\star}=\$ 67.20$ and the acquisition curve in Figure 1 , the optimal $A$ given by (11) is $\$ 9.49$ resulting in an acquisition rate of 29.27 per cent and $E P L V^{\star}=\$ 10.18$.

This completes the approach outlined by Blattberg and Deighton ${ }^{5}$ for helping managers balance the trade-off between acquisition and retention spending. The model makes several simplifying assumptions. Most notably, the model assumes constant margins and retention rates per period applied to a target group of homogeneous prospects. (To handle differences among prospects, the model can be applied separately to several smaller groups of homogenous prospects.) As pointed out in Thomas, ${ }^{6}$ the model also assumes that $A$ has no effect on the functional relationship between $R$ and $r$ when in fact, it probably should. In many situations, the aggressiveness of a firm's prospecting efforts affects not only the quantity of customers acquired, but also their quality. The model decision variables are $A$ and $R$, acquisition spending per prospect and retention spending per customer. The model yields recommended values for both these variables. Those recommendations should be understandable to the manager and actionable.

\section{Optimal cost to acquire and cost to retain}

The purpose of this paper is to explore the implications of the BD model with respect to optimal costs to acquire and costs to retain. Although these costs are not explicit parameters in the BD model, it is possible (using (3), (4), (6) and (7)) to transform the model's optimal spending levels into optimal costs to acquire and retain. In other words, because the BD model finds optimal 
Table 1: Complete results for the numerical example

\begin{tabular}{llll}
\hline & \multicolumn{2}{l}{ Acquisition } & Retention \\
\hline$C R$ & 0.4 & & 0.7 \\
$K$ & 0.1386 & & 0.0847 \\
$M$ & & $\$ 50$ & \\
$d$ & & 0.1 & \\
Optimal spending & $\$ 9.49$ & \multicolumn{2}{c}{$\$ 16.32$} \\
Average cost & $\$ 32.42$ & \multicolumn{2}{c}{$\$ 31.12$} \\
Marginal cost & $\$ 67.20$ & $\$ 67.20$ \\
$E P L V$ & & $\$ 10.18$ \\
$E C L V$ & & $\$ 67.20$ \\
\hline
\end{tabular}

spending amounts, it can also be used to determine what the firm's costs should be if they are spending optimally.

This exploration begins by calculating average and marginal costs for new and returning customers at the optimal spending levels in the numerical example. The costs are calculated using (3), (4), (6) and (7) and appear in Table 1. Table 1 is a complete summary of the numerical example. The first four rows are model inputs and the last four rows are model outputs.

At optimality, it will cost the firm (on average) $\$ 32.42$ to acquire a new customer and $\$ 31.12$ (on average) to retain an existing one. In other words, it should cost the firm (on average) 1.04 times as much to acquire a new customer as to retain an existing one. If the firm's current spending is such that they face the reported $5 \mathrm{X}$ ratio, they are not spending optimally. Two example $(A, R)$ spending pairs consistent with the $5 \mathrm{X}$ ratio are $(\$ 59.56, \$ 15)$ and $(\$ 70$, $\$ 20$ ). Notice that in both cases the firm is grossly overspending on acquisition. In the former case the firm underspends on retention while in the latter case it overspends.

In summary, this numerical example illustrates how the BD model provides a prescription for the optimal ratio of average cost per new customer to cost per retained customer. In this example, at optimality the ratio should be 1.04. If the firm's current ratio of average costs is $5 \mathrm{X}$, they are overspending on acquisition and could also be overspending on retention.

The picture for marginal costs is much clearer. At optimality, the marginal cost to acquire a new customer will equal the marginal cost to retain an existing customer, and both will equal ECLV ${ }^{\star}$. This result will be true (for the BD model) whenever $A^{\star}$ and $R^{\star}$ are positive.

The intuition behind this result is as follows. The marginal cost to acquire a customer increases with the amount the firm spends and the number of customers the firm expects to acquire. The expected value of each acquired customer is $E C L V^{\star}$. Consequently, the firm should acquire customers until the point where the marginal cost to acquire equals the value of the acquired customer. Because the value of each acquired customer is the constant $E C L V^{\star}$, the firm should spend up to the point where the marginal cost to acquire equals $E C L V^{\star}$.

To show this result algebraically, substitute $A^{\star}$ given by (11) in (1) to get the optimal acquisition rate

$$
a^{\star}=C R_{a}-\frac{1}{k_{a} E C L V^{\star}} .
$$

Substituting this optimal acquisition rate in (4) and simplifying shows that

$$
\left.A^{\prime}\right|_{a^{\prime}}=E C L V^{\star} \text {. }
$$

The marginal cost per acquired customer at the optimal acquisition rate equals the optimal ECLV. (This result also follows almost directly from (10). Taking the derivative of EPLV with respect to $a$ and setting it to zero shows that $A=E C L V^{\star}$ at $a^{\star}$.)

The intuition with respect to retention spending is similar. The marginal cost to retain an existing customer increases with 
the amount the firm spends and the number of customers it expects to retain. In the BD model, with its constant margins and retention rates, the expected value of each retained customer is ECLV. Consequently, the firm should retain customers until the point where the marginal cost to retain them equals the value of the retained customer. At optimality, marginal cost to retain will equal $E C L V^{\star}$, the value (at optimality) of the retained customer.

\section{THE CONSEQUENCES OF ACQUISITION COSTS 5X RETENTION COSTS}

This analysis of the BD model

demonstrates that the ratio of the marginal costs to acquire to the marginal cost to retain determines optimality. If the firm's marginal cost to acquire a customer is $5 \mathrm{X}$ the marginal cost to retain an existing customer, the firm is not at optimality. To move towards optimality, the firm must either increase its retention spending, decrease its acquisition spending or both. The BD model provides specific guidance on how to make those adjustments. So if the $5 \mathrm{X}$ refers to marginal costs, there are clear action implications in the BD model context.

Suppose instead that the $5 \mathrm{X}$ refers to average costs. Suppose the 'cost to acquire a new customer' was estimated as the ratio of total acquisition spending to total customers acquired. Also suppose that the 'cost to retain an existing customer' was estimated as the ratio of total retention spending to the total number of customer retained (in the period). In this situation, the $5 \mathrm{X}$ ratio refers to average cost as defined in this paper. If the firm's average cost to acquire a customer is $5 \mathrm{X}$ the average cost to retain an existing customer, are there clear action implications in the BD model context? The answer is no.
Table 2: Numerical example illustrating optimal $5 \mathrm{X}$ average cost ratio

\begin{tabular}{|c|c|c|}
\hline & Acquisition & Retention \\
\hline$C R$ & 0.4 & 0.95 \\
\hline$K$ & 0.2888 & 0.1440 \\
\hline$M$ & \multicolumn{2}{|c|}{$\$ 50$} \\
\hline$d$ & \multicolumn{2}{|c|}{0.1} \\
\hline Optimal spending & $\$ 2.41$ & $\$ 22.00$ \\
\hline Average cost & $\$ 120.20$ & $\$ 24.20$ \\
\hline Marginal cost & $\$ 173.70$ & $\$ 173.70$ \\
\hline$E P L V$ & \multirow{2}{*}{\multicolumn{2}{|c|}{$\begin{array}{l}\$ 1.07 \\
\$ 17370\end{array}$}} \\
\hline$E C L V$ & & \\
\hline
\end{tabular}

To illustrate, consider a carefully constructed numerical example delineated in Table 2.

Notice that at optimality, this firm should spend $\$ 2.41$ per prospect for a 2 per cent acquisition rate. The firm should spend $\$ 22.00$ per customer and retain 91 per cent of its customers. While the optimal expected lifetime value of a customer is $\$ 173.7$, the optimal expected value of a prospect is only $\$ 1.07$. This is a situation where new customers are difficult (expensive) to come by but valuable once acquired.

The point of this example (and the basis on which it was carefully constructed) is that at optimality, the firm's average cost to acquire a new customer is $5 \mathrm{X}$ its average cost to retain an existing customer. This example is the exception that proves the rule. The fact that a firm's average cost to acquire a customer is $5 \mathrm{X}$ its average cost to retain an existing customer is not reason enough to adjust spending. A $5 \mathrm{X}$ ratio of average costs can be exactly where a firm should be.

\section{DISCUSSION}

The purpose of this paper is explore whether a firm should spend more money on customer retention if its cost to acquire a new customer is $5 \mathrm{X}$ the cost to retain an existing one. Under the assumptions of the BD model, the 
answer depends on whether the costs in question are average or marginal. If the $5 \mathrm{X}$ ratio refers to average costs, then a $5 \mathrm{X}$ ratio does not necessarily imply the firm should spend more on retention. If the $5 \mathrm{X}$ ratio refers to marginal costs, the firm should either spend more on retention, less on acquisition or both. The BD model optimality condition requires that the marginal cost to acquire a customer equal the marginal cost to retain a customer and that both will equal the expected customer lifetime value.

This paper also demonstrates a shortcoming in the optimisation approach used in Blattberg and Deighton. ${ }^{7}$ Rather than select acquisition spending to maximise first year profits, expected prospect lifetime value should be the objective for a risk-neutral decision maker. A closed-form expression for the optimal acquisition-spending amount is provided.

To this point in the paper, no comment has been made on whether the costs in the $5 \mathrm{X}$ maxim refer to average or marginal costs. Because marginal costs are much more difficult to estimate, it is speculated that the quoted ratios refer to average costs. If the cost per acquired (retained) customer is estimated as the ratio of the amount spent on acquisition (retention) in a period to the number of customers acquired (retained), then the costs refer to average costs. If so, it is concluded that a ratio of five, six or 12 does not necessarily imply the firm should spend more on retention.

The unit of analysis of the BD model is the prospect. The BD model applies to a single prospect or to a known number of homogeneous prospects. It is for this reason the author prefers the term 'expected prospect lifetime value' to the term 'customer equity'. The value given by (8) is the value of a prospect, not a customer.
The diminishing returns inherent in the BD acquisition function (1) refer to the diminishing returns faced as the firm spends an increasing amount of money on a prospect. Another source of diminishing returns is the use of response modelling to rank prospects. As the firm contacts more prospects (in rank order), the resulting expected response rate goes down and the average cost per acquired customer goes up. A similar phenomenon occurs with retention. Consequently, an avenue of exploration is to see how the conclusions of this paper apply to situations where firms decide not only how much to spend per prospect, but how many prospects to contact. Such a model would be complicated by the necessity to incorporate a set of heterogeneous prospects and customers.

Because margins and retention rates are constant in the BD model, the expected value of a new customer is identical to the expected value of a returning customer. Consequently, the optimal marginal cost to acquire should equal the optimal cost to retain and both should equal the optimal expected customer lifetime value. As argued by Reichheld and others, however, returning customers are usually more valuable than new customers. ${ }^{8}$ The sources of extra value are increased retention rates, increased revenues, decreased costs to serve and decreased costs to retain. If returning customers are more valuable it is speculated that the marginal cost to retain an existing customer should exceed the marginal cost to acquire a new one at optimality. A model that includes growing margins and changing retention rates will be needed to verify this speculation. A challenge in modelling changing retention rates will be to do so in a way that allows a meaningful analysis of the relationships between retention spending and the set of changing retention rates. 


\section{References}

1 Blattberg, R. C. and Deighton, J. (1996) 'Manage marketing by the customer equity test', Harvard Business Review, July-August, pp. 136-144.

2 Sterne, J. (2002) 'Web metrics: proven methods for measuring web site success', John Wiley \& Sons, New York, p. 283.

3 Blattberg and Deighton (1996) op. cit.

4 Ibid.
5 Ibid.

6 Thomas, J. (2001) 'A methodology for linking customer acquisition and retention', Journal of Marketing Research, Vol. XXXVIII, pp. 262-268.

7 Blattberg and Deighton (1996) op. cit.

8 Reichheld, F. F. (1996) 'The loyalty effect: The hidden force behind growth, profits, and lasting value', Harvard Business School Press, Boston. 